\title{
Application of CZE Method in Routine Analysis for Determination of B-Complex Vitamins in Pharmaceutical and Veterinary Preparations
}

\author{
Marina Franco, Renata Jasionowska, and Elisa Salvatore \\ Dipartimento di Chimica, Sapienza Università, 00185 Roma, Italy \\ Correspondence should be addressed to Marina Franco, marina.franco@uniroma1.it
}

Received 12 July 2011; Revised 28 December 2011; Accepted 9 January 2012

Academic Editor: Mohamed Mohamed

Copyright () 2012 Marina Franco et al. This is an open access article distributed under the Creative Commons Attribution License, which permits unrestricted use, distribution, and reproduction in any medium, provided the original work is properly cited.

\begin{abstract}
A competitive CZE method for quality control analysis of multivitamin preparations and veterinary products containing B-group vitamins was developed. Vitamins of interest are thiamine hydrochloride $\left(B_{1}\right)$, thiamine monophosphate chloride $\left(B_{1 a}\right)$, riboflavine $\left(B_{2}\right)$, riboflavine-5' monophosphate $\left(B_{2 a}\right)$, nicotinamide $\left(B_{3}\right)$, d-pantothenic acid calcium salt $\left(B_{5}\right)$, pyridoxine hydrochloride $\left(B_{6}\right)$, folic acid $\left(B_{9}\right)$, and 4-aminobenzoic acid $\left(B_{10}\right)$. These analytes were separated optimizing the experimental conditions in $20 \mathrm{mM}$ tetraborate buffer $\mathrm{pH}=9.2$ as a BGE (background electrolyte), on a Beckman P/ACE System MDQ instrument, using uncoated fused silica capillary. The effective capillary length was of $49.5 \mathrm{~cm}$, I.D. $=50 \mu \mathrm{m}$, the applied voltage $20 \mathrm{kV}$ and the temperature $25^{\circ} \mathrm{C}$. Detection was performed by a diode array detector at $214 \mathrm{~nm}$ for all vitamins except $B_{5}(190 \mathrm{~nm})$ and $B_{2 a}(260 \mathrm{~nm})$. Separation time was about $9 \mathrm{~min}$. After experimental conditions optimization, the proposed method was validated. Precision of migration time and corrected peak area, linearity range, LOD and LOQ, accuracy (recovery), robustness, and ruggedness were evaluated for each analyte demonstrating the good reliability of the method. Analyses of the pharmaceutical real samples were performed and confirmed the versatility of this method.
\end{abstract}

\section{Introduction}

Quality control (QC) plays an essential role in the pharmaceutical industry. In fact many analytical methods, employing different techniques, are being developed for evaluation of pharmaceutical preparations. Vitamins of B group were well separated by RP-HPLC. A method for the simultaneous determination of taurine and 10 water-soluble vitamins including vitamin $\mathrm{B}_{1}$ (thiamine), $\mathrm{B}_{2}$ (riboflavine), $\mathrm{B}_{5}$ (pantothenic acid), $\mathrm{B}_{6}$ (pyridoxine and pyridoxal), $\mathrm{B}_{8}$ (biotin), $\mathrm{B}_{9}$ (folic acid), $\mathrm{C}$ (ascorbic acid), and $\mathrm{B}_{3}$ (nicotinamide and nicotinic acid) in multivitamin tablets was developed and validated. Detection of components was by ESI-MS [1]. Some water-soluble vitamins of our interest (ascorbic acid, thiamine hydrochloride, riboflavine- $5^{\prime}$-phosphate sodium, pyridoxine hydrochloride, nicotinamide, and (+)panthenol) and two preservatives (methylparaben and sodium benzoate) in multivitamin syrup were well-separated on Zorbax SB-Aq (C18) column [2]. A HPLC-UV method was established for the simultaneous determination of eight vitamins, including $\mathrm{B}_{1}, \mathrm{~B}_{2}, \mathrm{~B}_{3}, \mathrm{~B}_{6}, \mathrm{~B}_{9}$, cyanocobalamin, ascorbic acid in baby milk powder [3]. A validated HPLC-UV method for the determination of seven B-complex vitamins $\left(\mathrm{B}_{1}, \mathrm{~B}_{2}, \mathrm{~B}_{3}, \mathrm{~B}_{6}, \mathrm{~B}_{9}\right.$, and cyanocobalamin) in pharmaceuticals and biological fluids after solid-phase extraction was performed [4]. Simultaneous determination of water- and fatsoluble vitamins in pharmaceutical preparations by HPLC was performed in a single run using combined isocratic and linear gradient elution with a mobile phase consisting of trifluoroacetic acid and methanol. The method was applied for real sample. The results were in good agreement with the declared values. Vitamins analyzed were $\mathrm{B}_{1}, \mathrm{~B}_{2}, \mathrm{~B}_{5}, \mathrm{~B}_{6}, \mathrm{~B}_{9}$, $\mathrm{B}_{3}$, and $\mathrm{B}_{12}$ (cyanocobalamin) [5].

The RP ion-pair HPLC method was applied for determination of some vitamins of our interest in multivitamin with minerals from different authors. For nicotinamide, pyridoxine hydrochloride, thiamine mononitrate and riboflavine a HPLC method was validated using methanol $0.5 \%$ acetic acid as the mobile phase [6]. 
A sensitive RP-HPLC method was developed and validated for the simultaneous determination of $\mathrm{B}_{1}, \mathrm{~B}_{3}, \mathrm{~B}_{6}$, and $\mathrm{B}_{9}$ in Pentovit coated tablets. The procedures were carried out on a Supelcosil ABZ column with methanol, heptanesulfonic acid sodium salt, and triethylamine as the mobile phase [7]. For the determination of thiamine and riboflavine in Duoweiyuansu Tablet an HPLC-UV method was established. The mobile phase consisted of ion-pairing reagent (containing 1-hexanesulfonate, glacial acetic acid, and triethylamine)/methanol $(80: 20)$. The method can be used for the quality control of thiamine and riboflavine in Duoweiyuansu Tablet [8]. There are many papers about vitamins of B group analysed by capillary electrophoresis (CE) and its modifications. Some authors studied determination of vitamins in food based on supercritical fluid extraction prior to micellar electrokinetic capillary chromatographic (MEKC) analyses of individual components. The method was optimized using sodium cholate as the micellar phase for the separation of $11 \mathrm{~B}$-vitamins, ascorbic acid, and 4 impurities in about $25 \mathrm{~min}$ [9]. Other authors investigated in capillary zone electrophoresis (CZE) analysis the effect of lower organic alcohols as cosurfactants (methanol, ethanol, n-propanol, isopropanol, propanediol, n-butanol and isoamyl alc.) and n-hexane as an organic modifier in phosphate buffer with varying SDS concentration using a set of vitamins and p-hydroxybenzoic acid as the test mixture. Optimum separations were achieved particularly at high concentrations of the surfactant [10]. The CZE analyses of three vitamins $\left(B_{1}, B_{2}\right.$, and $B_{6}$ in tablets achieved using phosphate-borate buffer $\mathrm{pH} 9.0$ short time of analysis (5 min) [11]. One year later the same authors studied another specific, precise, sensitive, and accurate method for separation of the same vitamins obtaining high separation efficiency and shorter analysis time (3 min) [12]. Four B vitamins, as $B_{1}, B_{2}$, pyridoxal, pyridoxine, and pyridoxamine $\left(B_{6}\right)$ in a pharmaceutical product were determined simultaneously using CZE. An $\mathrm{HCl}$ soln. was used for the extraction of the vitamins from a multivitamin-multimineral tablet. BGE employed was sodium phosphate buffer ( $\mathrm{pH} 9.0$ ) [13].

Mixture of four water-soluble B-group vitamins were analysed both by CZE and MECK. The quantitative analyses of different pharmaceutical formulations were compared with the LC method of the US Pharmacopeia obtaining a good correlation [14].

Rapid methods were developed for simultaneously separation of five vitamins: $B_{1}, B_{2}, B_{6}$, nicotinamide, nicotinic, and ascorbic acid. They were tested on 15 real samples obtaining good resolution by (CZE) and (MECC). CZE was performed with $0.02 \mathrm{M}$ borate buffer, while MECC in $0.02 \mathrm{M}$ borate/phosphate buffer with $4 \%$ acetonitrile containing. $0.1 \mathrm{M}$ sodium dodecyl sulfate [15].

Some authors studied a method for the analysis of six water-soluble vitamins (thiamine, nicotinamide, riboflavin, pyridoxine, pantothenic, and ascorbic acid) in a pharmaceutical formulation, by CZE. A good compromise between resolution, analysis time, and analyte stability was obtained by use of a $50 \mathrm{mM}$ borax buffer of $\mathrm{pH}$ 8.5. This CZE method was very useful for the separation of more complex samples, but cyanocobalamin could not be separated from nicotinamide in this CZE system. In fact the 2 compounds were in uncharged form the $\mathrm{pH}$ used. Instead, they were resolved by MECC using SDS in BGE. Good results with respect to linearity, precision, and accuracy were obtained in the concentration range studied for the 6 vitamins [16].

There are some studies about B-complex by spectrophotometric methods.

Spectrophotometric determination of ternary mixtures of thiamine, riboflavin, and pyridoxal in pharmaceutical and human plasma by least-squares support vector machines were performed. The partial least squares (PLS) modelling and least-squares support vector machines were used for the multivariate calibration of the spectrophotometric data [17]. The same procedure was applied successfully for determination of $B_{1}, B_{2}, B_{3}$, and $B_{6}$ in pharmaceuticals by other authors [18].

Simultaneous determination of fourteen water-soluble vitamins (13 of B-group and vitamin C) in selected food matrices by LC/MS/MS technique is described in a recent paper [19]. Analytes were separated in less than $10 \mathrm{~min}$ with recoveries between $30 \%$ and $70 \%$.

The QC process in pharmaceutical industry needs methods that are able to determine, in a single run, the majority of components. In many cases, to determine all components of a multivitamin pharmaceutical preparation, it is necessary to perform different analyses applying different techniques.

Capillary electrophoresis (CE) is a powerful analytical technique that is widely used in research, and in quality control of pharmaceuticals. As demonstrated exploring the literature data, the MEKC was the only method [9] able to separate up to $11 \mathrm{~B}$-group vitamins. Other CE methods offer the possibility to separate only a few $(\max 5)$ molecules of this class. There are no publications about simultaneous determination of nine B-group vitamins by CZE, the simplest in CE system, which offers several advantages over HPLC such as rapid analysis, lower solvent consumption, then lower costs and minor environmental impact, and higher efficiency.

For this purpose, the aim of this work is to develop a validated CZE method for assay of a multicomponent pharmaceutical and veterinary formulations in routine analysis.

\section{Experimental}

2.1. Apparatus. The analyses were carried out on a P/ACE system from Beckman Instrument Fullerton, CA (USA), with a UV-DAD detector. For ruggedness evaluation, electrophoretic separations were carried out on the SpectraPhoresis 1000 instrument from Thermo-Quest Corporation, CA (USA).

The uncoated fused silica capillary ID $=50 \mu \mathrm{m}, 59.5 \mathrm{~cm}$ total length and $49.5 \mathrm{~cm}$ effective length was supplied by SGE (Melbourne, Australia). Detection wavelength was set at $214 \mathrm{~nm}$. The sample injections were performed in a hydrodynamic mode ( $5 \mathrm{~s}$ under $0.5 \mathrm{psi}$ ).

\subsection{Chemicals and Materials. All reagents were of analytical} grade purity. 
Borax, disodium hydrogen phosphate dihydrate, sodium dihydrogen phosphate monohydrate, potassium chloride, and CTAB (Cetyl trimethylammonium bromide) were from FLUKA (Buchs, Switzerland). Phosphoric acid, sodium hydroxide, chloric acid, and acetonitrile were supplied by Carlo Erba (Milan, Italy). Trizma base (Tris [hydroxymethyl] aminomethane), EDTA (ethylenediaminetetraacetic acid). Sodium bicarbonate, citric acid, oxalic acid, and sodium bitartrate monohydrate were from Sigma-Aldrich (Steinheim, Germany).

The real samples were commercially available pharmaceutical products: Berocca Plus (Bayer S.p.A), Gabbrovital B forte (CEVA VETEM SpA), Trinidex (LDB LAB.DIACO BIOMEDICALI SpA), and Biochetasi (Sigma-Tau SpA). For solution filtering the syringe filters $0.45 \mu \mathrm{m}$ (Millex HV, Millipore, MA, USA) were used.

2.2.1. The Standards of Vitamins. thiamine hydrochloride $\left(B_{1}\right)$, thiamine pyrophosphate chloride $\left(B_{1 a}\right)$, riboflavine $\left(B_{2}\right)$, riboflavine- $5^{\prime}$ monophosphate $\left(B_{2 a}\right)$, nicotinamide $\left(B_{3}\right)$, d-pantothenic acid calcium salt $\left(B_{5}\right)$, pyridoxine hydrochloride $\left(\mathrm{B}_{6}\right)$, biotin $\left(\mathrm{B}_{8}\right)$, folic acid $\left(\mathrm{B}_{9}\right), \mathrm{B}_{10}$ (4-aminobenzoic acid), cyanocobalamin $\left(\mathrm{B}_{12}\right)$, hydroxocobalamin $\left(B_{12 a}\right)$, and 2-3 dihydroxybenzoic acid were purchased from Fluka (Buchs, Switzerland).

2.3. Standard, Buffer, and Real Sample Preparation. Standard stock solutions of studied analytes (at $1 \mathrm{mg} / \mathrm{mL}$ concentration) were prepared in distilled water, riboflavine and folic acid were dissolved in $\mathrm{HCl}$, respectively, $3 \mathrm{M}$ and $2 \mathrm{M}$.

The calibration solutions were obtained by dilution of the stock solution with distilled water to give a desired analyte concentration. The real samples preparation was different for each product.

For Berocca Plus preparation, twenty tablets were weighted and grounded in a mortar. The quantity of powder equivalent at one tablet was weighted and dissolved in a $50 \mathrm{~mL}$ volumetric flask with distilled water. After sonication for $10 \mathrm{~min}$ in an ultrasonic bath, the supernatant solution was centrifuged for $5 \mathrm{~min}$ and then filtered through the $0.45 \mu \mathrm{m}$ syringe filter. Finally the solution was diluted with distilled water to reach a concentration order inside the calibration range.

For Trinidex sample, the intravenous injection solution was filtered through the $0.45 \mu \mathrm{m}$ syringe filter without dilution and injected.

For Gabbrovital preparation, the veterinary intramuscular injection solution was diluted $1: 1000$ because of its high concentration, then filtered and analysed.

For Biochetasi sample, the powder contained in the vial for the intramuscular injection, was diluted with distilled water to reach a desired concentration and then filtered through the $0.45 \mu \mathrm{m}$ syringe filter.

\section{Results and Discussion}

3.1. Method Development and Optimization. In order to propose a suitable method for routine analysis, it was neces- sary to evaluate the experimental conditions for the best resolution of studied analytes.

First, because of different solubility and stability for each vitamin, many conditions for their dissolution were tested. Several parameters for the CZE analysis, such as BGE composition and concentration, $\mathrm{pH}$, injection conditions, wavelengths, applied voltage, and temperature were explored.

\subsubsection{Effect of BGE Composition, Concentration, and $p H$.} The BGE buffer composition is one of the most important parameters in capillary electrophoresis.

In order to obtain maximum precision level, it is necessary to choose the buffer very carefully.

Most of vitamins are nitrogen-containing, protonable molecules, so starting point of this work was to explore the low range of $\mathrm{pH}$ values for their separation.

In the preliminary step of study, the BGEs tested $\mathrm{pH}$ ranging between 1.5-4.2 and concentration ranging between $20 \mathrm{mM}$ to $50 \mathrm{mM}$, are $\mathrm{HCl} / \mathrm{KCl}$, phosphate, phosphateoxalate, phosphate with $5 \%$ acetonitrile, phosphate with $\mathrm{CTAB}$, phosphate-tartrate, and tartrate.

Only in $20 \mathrm{mM}$ phosphate buffer at $\mathrm{pH}=2.3$ good separation of eleven analytes was realised in about 23 minutes. In Figure 1, analytes from 1 to 7 are cations, the others $(8-10)$ are in anionic form. In these operating conditions, riboflavine $\left(\mathrm{B}_{2}\right)$ and cyanocobalamin $\left(\mathrm{B}_{12}\right)$ are overlaid. Since these compounds are often contained in the same pharmaceutical preparation, it is impossible to determinate both of them. Long analysis time, high intensity of current, and low repeatability of migration time (RSD\% 10\%) did not allow to propose this procedure for routinely analyses.

Consequently the possibility of separation of studied vitamins in alkaline buffers were evaluated.

BGE buffers at $\mathrm{pH}$ between 8.5 and 9.3 into the range of concentration $20 \mathrm{mM}$ to $80 \mathrm{mM}$ were explored: tris/ $\mathrm{HCl}$, bicarbonate/carbonate, tris/borate, borate, borate with EDTA, and borate with CTAB.

Best separation of nine vitamins was realized in $20 \mathrm{mM}$ borate buffer at $\mathrm{pH} 9.2$ in about 9 minutes (Figure 2).

The peaks are symmetric and baseline resolved for individual $\mathrm{B}$ vitamins with exception of d-pantothenic acid calcium salt $\left(\mathrm{B}_{5}\right)$ and riboflavine- $5^{\prime}$ monophosphate $\left(\mathrm{B}_{2 \mathrm{a}}\right)$, that are coeluted. Since a good compromise between peak symmetry, resolution, and analysis time resulted in $20 \mathrm{mM}$ borate buffer at $\mathrm{pH}=9.2$, these experimental conditions were chosen as optimal.

3.1.2. Effect of Wavelength. Primarily it was necessary to select the most suitable wavelength for the simultaneous detection of vitamins, since spectral properties of each one differs enough. The UV spectra obtained by UV-DAD show three suitable wavelengths for quantitative analysis. $214 \mathrm{~nm}$ for all the vitamins, at exception of d-pantothenic acid calcium salt $\left(\mathrm{B}_{5}\right)$ and riboflavine- $5^{\prime}$ monophosphate $\left(\mathrm{B}_{2 \mathrm{a}}\right)$, that are overlaid. Then the quantitative analysis of these two analytes was realized at the wavelengths of 190 and $260 \mathrm{~nm}$, because the considered compounds do not interfere themselves. In fact vitamin $B_{5}$ has only maximum of absorbance at $190 \mathrm{~nm}$, 


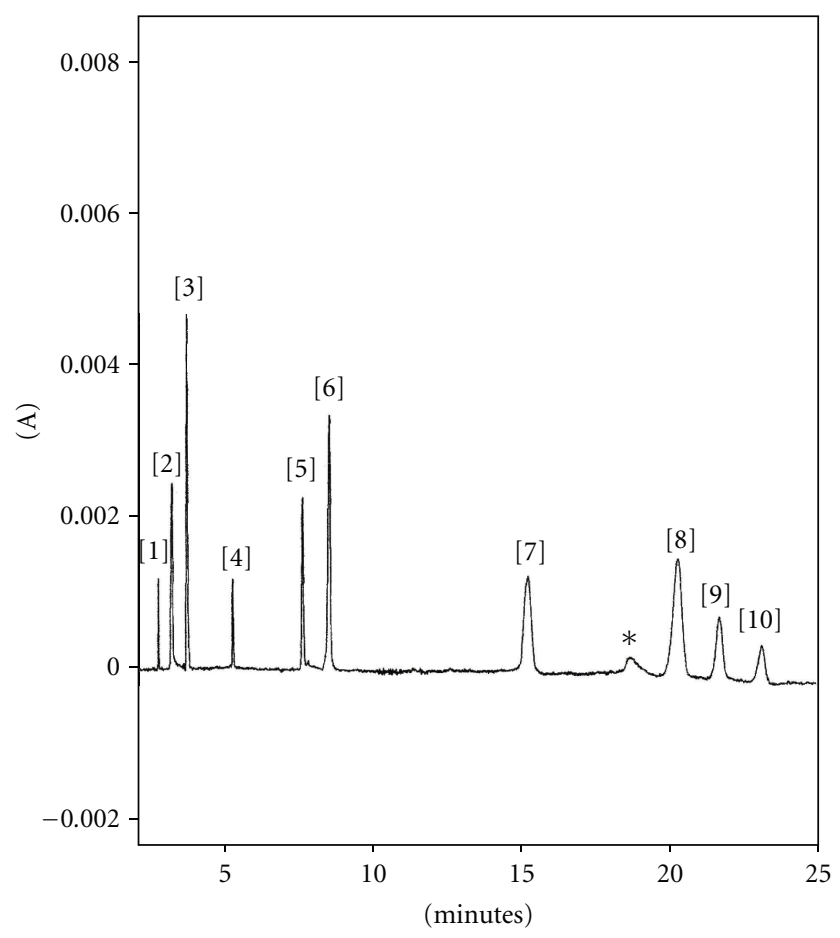

FIgure 1: Electropherogram of standard mixture in acidic BGE. Peak identification: (1) $\mathrm{B}_{1} 20 \mu \mathrm{g} / \mathrm{mL}$; (2) $\mathrm{B}_{3} 10 \mu \mathrm{g} / \mathrm{mL}$; (3) $\mathrm{B}_{6} 5 \mu \mathrm{g} /$ $\mathrm{mL}$; (4) $B_{12 \mathrm{a}} 20 \mu \mathrm{g} / \mathrm{mL}$; (5) $B_{1 \mathrm{a}} 10 \mu \mathrm{g} / \mathrm{mL}$; (6) $\mathrm{B}_{10} 5 \mu \mathrm{g} / \mathrm{mL}$; (7) $\mathrm{B}_{9}$ $15 \mu \mathrm{g} / \mathrm{mL} ;(8) \mathrm{B}_{2}+\mathrm{B}_{12}(10+20) \mu \mathrm{g} / \mathrm{mL} ;$ (9) $\mathrm{B}_{7} 10 \mu \mathrm{g} / \mathrm{mL} ;(10)$ $\mathrm{B}_{5} 40 \mu \mathrm{g} / \mathrm{mL}$. Experimental conditions: phosphate buffer $20 \mathrm{mM}$; $\mathrm{pH}=2.3 ; V=30 \mathrm{kV} ; i=80 \mu \mathrm{A} ; \mathrm{T}=25^{\circ} \mathrm{C}$; injection at $0.5 \mathrm{psi}$ for $5 \mathrm{~s}$, fused silica capillary i.d. $=50 \mu \mathrm{m}, L=59.5 \mathrm{~cm}, l=49.5 \mathrm{~cm}$ instrument P/ACE MDQ System (Beckman).

while vitamin $\mathrm{B}_{2 \mathrm{a}}$ presents two maximums at 214 and $260 \mathrm{~nm}$.

3.1.3. Effect of Applied Voltage. For the optimization of separation voltage the analyses ranging the applied voltage between 10 and $30 \mathrm{kV}$ were carried out. At low voltage the separation of all the analytes was reached but the analysis time increased to $20 \mathrm{~min}$ with the broadening of peaks. Increasing the voltage $(\max 30 \mathrm{kV})$ the optimal value results in $20 \mathrm{kV}$ producing the current intensity of $25 \mathrm{uA}$ and good repeatability. At $30 \mathrm{kV}$ the separation of analytes was incomplete.

3.1.4. Effect of Temperature. The increase of temperature $\left(30^{\circ} \mathrm{C}\right)$ produced the shortening of analysis time (the viscosity of the BGE decrease). It should be advantageous setting high temperature of cartridge but B-complex is thermolabile. So the suitable temperature for analyses of these compounds resulted in $25^{\circ} \mathrm{C}$.

3.2. Method Validation. The method was validated following the ICH guideline [20].

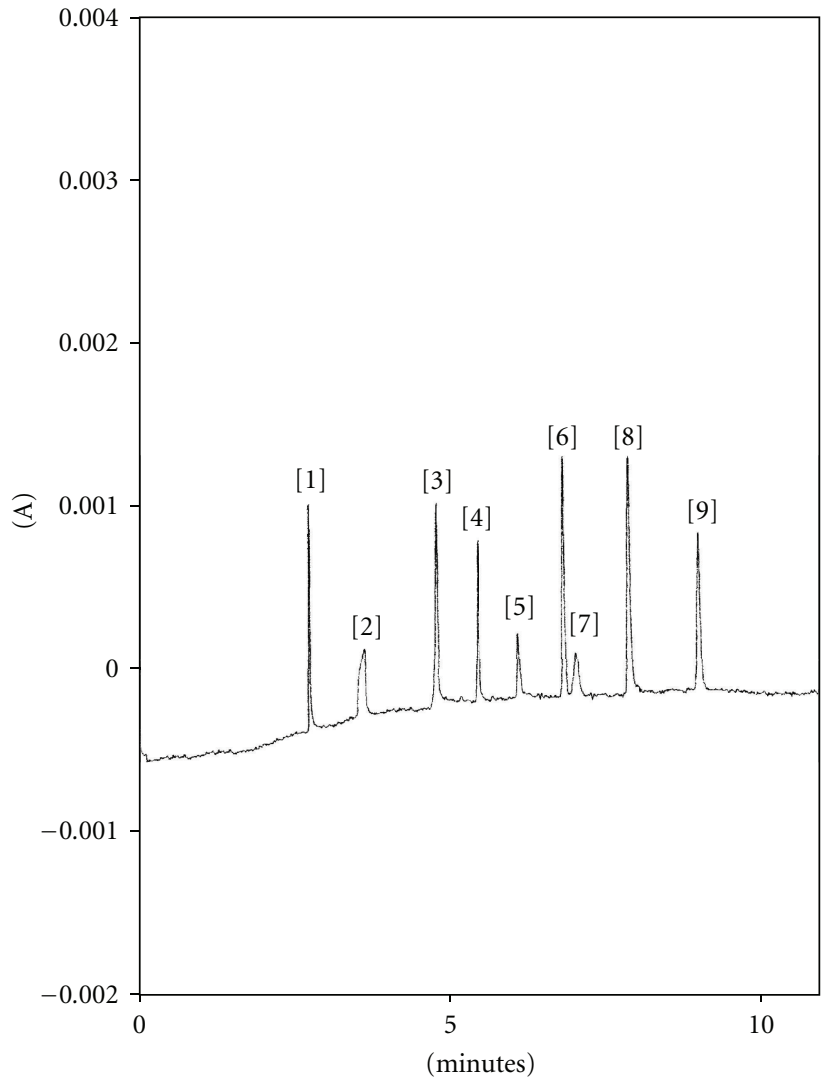

FIGURE 2: Electropherogram of standard mixture in basic BGE. Peak identification: (1) $\mathrm{B}_{1} 20 \mu \mathrm{g} / \mathrm{mL}$; (2) $\mathrm{B}_{3} 10 \mu \mathrm{g} / \mathrm{mL}$; (3) $\mathrm{B}_{2} 10 \mu \mathrm{g} / \mathrm{mL}$; (4) $\mathrm{B}_{6} 5 \mu \mathrm{g} / \mathrm{mL}$; (5) $\mathrm{B}_{1 \mathrm{a}} 10 \mu \mathrm{g} / \mathrm{mL}$; (6) $\mathrm{B}_{10} 5 \mu \mathrm{g} / \mathrm{mL}$; (7) $\mathrm{B}_{5}+\mathrm{B}_{2 \mathrm{a}}$ $(40+10) \mu \mathrm{g} / \mathrm{mL}$; (8) S.I. $3 \mu \mathrm{g} / \mathrm{mL}$; (9) $\mathrm{B}_{9} 20 \mu \mathrm{g} / \mathrm{mL}$. Experimental conditions: borate buffer $20 \mathrm{mM} ; \mathrm{pH}=9.2 ; V=20 \mathrm{kV} ; i=25 \mu \mathrm{A}$; $T=25^{\circ} \mathrm{C} ; t_{i n j}=5 \mathrm{~s} p_{i n j}=0.5$ psi fused silica capillary ID $=50 \mu \mathrm{m} ; L$ $=59.5 \mathrm{~cm} ; l=49.5 \mathrm{~cm}$, instrument P/ACE MDQ System (Beckman).

3.2.1. Precision. The precision was evaluated in terms of RSD\% of migration time $\left(t_{m}\right)$ and corrected peak area $\left(A_{c}\right)$ for intraday and interday analyses. For the intra-day precision evaluation the standard solutions at three concentrations levels (low, intermediate, and high) were injected in the same day. To estimate the interday precision, the standard solutions were analysed for five consecutive days performing five consecutive injections every day. The calculated RSD\% values are reported in Table 1.

3.2.2. Calibration Range. The linearity of detector response was tested in different ranges as reported in Table 2. For the quantitative analysis the Internal Standard method was applied. For its property, was choosen Internal Standard 3,4 dihydroxy-benzoic acid.

Six standard solutions, containing nine analytes of interest and the Internal Standard, were injected in triplicate. The calibration lines were obtained plotting $\mathrm{R}$ (corrected areas ratio) versus the standard solutions concentration using Microsoft EXCEL. 
TABLE 1: Intraday and interday precision of migration time $\left(t_{m}\right)$ and corrected peak area $\left(A_{c}\right)$ in optimal condition at low-, intermediate-, and high-concentration levels.

\begin{tabular}{|c|c|c|c|c|c|c|}
\hline & & & & & & \\
\hline & Intraday & Interday & & & & \\
\hline & Hitiday & Hinteray & Low & Intermediate & High & Intermediate \\
\hline $\mathrm{B}_{1}$ & 0.20 & 0.31 & 5.51 & 2.89 & 1.76 & 4.37 \\
\hline $\mathrm{B}_{3}$ & 0.17 & 0.57 & 3.16 & 2.54 & 2.30 & 4.31 \\
\hline $\mathrm{B}_{2}$ & 0.24 & 0.99 & 4.89 & 1.89 & 1.41 & 4.15 \\
\hline $\mathrm{B}_{6}$ & 0.32 & 0.77 & 5.48 & 2.39 & 1.91 & 3.22 \\
\hline $\mathrm{B}_{1 \mathrm{a}}$ & 0.34 & 0.81 & 6.29 & 1.95 & 1.26 & 3.87 \\
\hline $\mathrm{B}_{10}$ & 0.32 & 0.95 & 3.83 & 1.91 & 2.14 & 4.28 \\
\hline $\mathrm{B}_{5}$ & 0.27 & 0.87 & 4.91 & 1.04 & 1.56 & 3.17 \\
\hline $\mathrm{B}_{2 \mathrm{a}}$ & 0.34 & 0.57 & 5.00 & 2.59 & 1.51 & 4.91 \\
\hline SI & 0.34 & 0.82 & 4.51 & 2.15 & 1.99 & 2.61 \\
\hline $\mathrm{B}_{9}$ & 0.38 & 1.01 & 5.74 & 1.16 & 2.84 & 4.33 \\
\hline
\end{tabular}

TABLE 2: Method linearity data.

\begin{tabular}{lccr}
\hline Analyte & Calibration range $\mu \mathrm{g} / \mathrm{mL}$ & Equation & $r^{2}$ \\
\hline $\mathrm{B}_{1}$ & $5-200$ & $y=0.0235 x-0.0111$ & 0.9952 \\
$\mathrm{~B}_{3}$ & $10-120$ & $y=0.0722 x-0.2297$ & 0.9931 \\
$\mathrm{~B}_{2}$ & $5-40$ & $y=0.0742 x-0.0104$ & 0.9989 \\
$\mathrm{~B}_{6}$ & $3-40$ & $y=0.0597 x-0.0024$ & 0.9993 \\
$\mathrm{~B}_{1 \mathrm{a}}$ & $5-40$ & $y=0.0183 x-0.0194$ & 0.9956 \\
$\mathrm{~B}_{10}$ & $3-25$ & $y=0.0887 x-0.0240$ & 0.9973 \\
$\mathrm{~B}_{5}$ & $30-120$ & $y=0.0077 x-0.0666$ & 0.9970 \\
$\mathrm{~B}_{2 \mathrm{a}}$ & $5-40$ & $y=0.0224 x+0.0053$ & 0.9972 \\
$\mathrm{~B}_{9}$ & $5-30$ & $y=0.0557 x-0.0488$ & 0.9912 \\
\hline
\end{tabular}

TABLE 3: Commercial product analysis.

\begin{tabular}{|c|c|c|c|c|c|c|c|c|}
\hline \multirow[t]{3}{*}{ Commercial product } & \multicolumn{2}{|c|}{ Berocca plus } & \multicolumn{2}{|c|}{ Gabbrovital B } & \multicolumn{2}{|c|}{ Trinidex } & \multicolumn{2}{|c|}{ Biochetasi } \\
\hline & \multicolumn{2}{|c|}{$\mathrm{mg} / \mathrm{tab}$} & \multicolumn{2}{|c|}{$\mathrm{mg} / 100 \mathrm{~mL}$} & \multicolumn{2}{|c|}{$\mathrm{mg} / 100 \mathrm{~mL}$} & \multicolumn{2}{|c|}{$\mathrm{mg} / \mathrm{vial}$} \\
\hline & Found & Declared & Found & Declared & Found & Declared & Found & Declared \\
\hline $\mathrm{B}_{1}$ & $1.55 \pm 0.06$ & 1.54 & $15.24 \pm 0.38$ & 15.00 & $0.98 \pm 0.05$ & 1.00 & - & - \\
\hline $\mathrm{B}_{1 \mathrm{a}}$ & - & - & - & - & - & - & $40.41 \pm 1.20$ & 47.00 \\
\hline $\mathrm{B}_{2}$ & $1.77 \pm 0.36$ & 1.76 & - & - & - & - & - & - \\
\hline $\mathrm{B}_{2 \mathrm{a}}$ & - & - & - & - & - & - & $31.10 \pm 1.19$ & 28.30 \\
\hline $\mathrm{B}_{3}$ & $17.93 \pm 0.97$ & 18.00 & $3.03 \pm 0.17$ & 3.00 & $11.03 \pm 0.91$ & 10.00 & - & - \\
\hline $\mathrm{B}_{5}$ & $6.48 \pm 0.50$ & 6.60 & - & - & - & - & - & - \\
\hline $\mathrm{B}_{6}$ & $2.18 \pm 0.11$ & 2.20 & $1.50 \pm 0.03$ & 1.50 & $20.18 \pm 0.24$ & 20.00 & $12.35 \pm 0.23$ & 15.00 \\
\hline $\mathrm{B}_{9}$ & $0.24 \pm 0.03$ & 0.25 & - & - & - & - & - & - \\
\hline
\end{tabular}

3.2.3. $L O D$ and LOQ. LOD, the lowest concentration of analytes that can be distinguished from the noise, defined as signal to noise ratio $\mathrm{S} / \mathrm{N}$ of $3: 1$ was ranging between $0.9 \mu \mathrm{g} / \mathrm{mL}$ to $9.0 \mu \mathrm{g} / \mathrm{mL}$.

LOQ, the lowest concentration of analytes that can be quantified with good precision, defined as signal to noise ratio $\mathrm{S} / \mathrm{N}$ of $10: 1$ was ranging between $3.0 \mu \mathrm{g} / \mathrm{mL}$ to $30.0 \mu \mathrm{g} / \mathrm{mL}$.
3.2.4. Analysis of Real Samples. Four pharmaceutical formulation containing B-complex vitamins were analyzed. The experimental results are given in Table 3. No interference was observed in pharmaceutical solutions. RSD\% of migration time and corrected peak area values were lower, respectively, than $0.5 \%$ and $3.0 \%$. A typical electropherogram of commercial pharmaceutical preparation (Berocca Plus) is shown in Figure 3. 


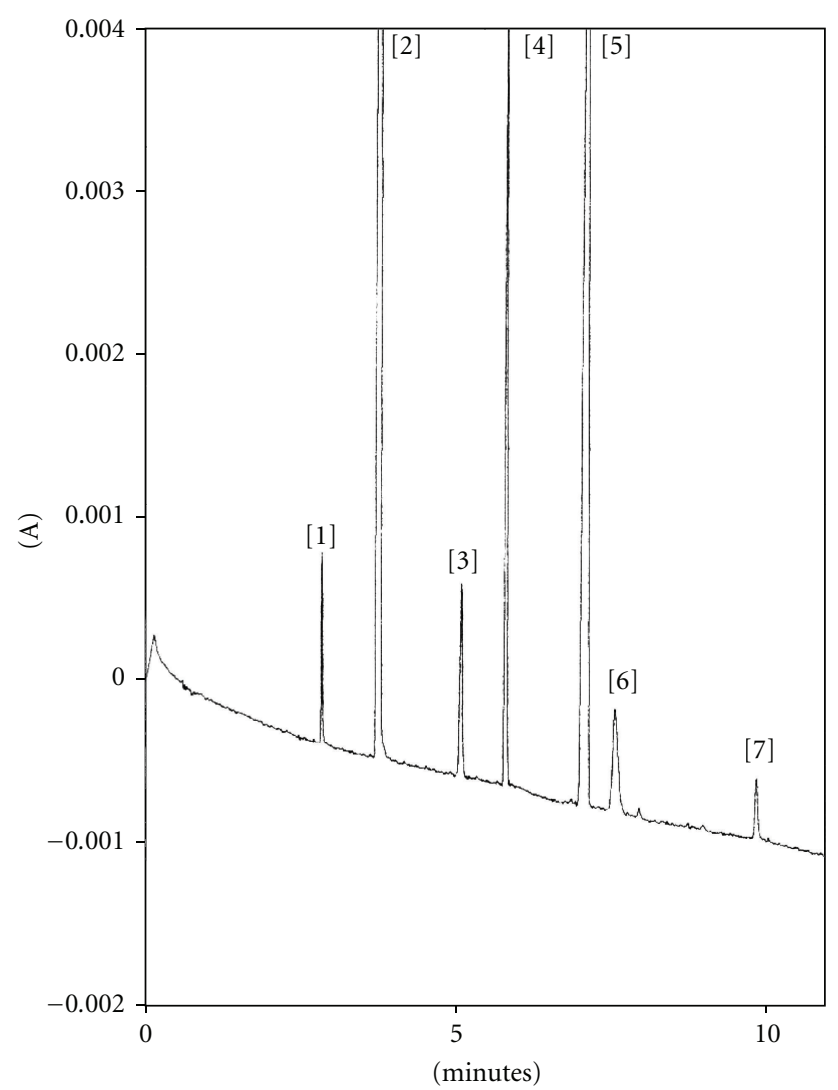

Figure 3: Electropherogram of real sample Berocca Plus. Experimental conditions: see Figure 2. Peak identification: (1) $\mathrm{B}_{1} 31 \mu \mathrm{g} /$ $\mathrm{mL}$; (2) $\mathrm{B}_{3} 36 \mu \mathrm{g} / \mathrm{mL}$; (3) $\mathrm{B}_{2} 35 \mu \mathrm{g} / \mathrm{mL}$; (4) $\mathrm{B}_{6} 40 \mu \mathrm{g} / \mathrm{mL}$; (5) ascorbic acid (not determined); (6) $\mathrm{B}_{9} 5 \mu \mathrm{g} / \mathrm{mL}$; (7) SI $3 \mu \mathrm{g} / \mathrm{mL}$. The concentrations are the nominal values.

3.2.5. Accuracy. Accuracy was evaluated by recovery assays on the commercial product. After fortification, the real sample undergo the analysis and the resulted concentration were compared with the data obtained without fortification. The resulting recoveries data are ranging from 97.0 to $101.4 \%$.

3.2.6. Ruggedness. For this purpose, measurements on the SpectraPhoresis 1000 apparatus in the optimal experimental conditions were performed. In this instrument the cartridge form is different and the capillary total length is $44 \mathrm{~cm}$, the effective length $36 \mathrm{~cm}$ (shorter than optimal length of capillary utilized on the Beckman instrument). Consequently, on this instrument, it was necessary to apply lower voltage $(10 \mathrm{kV})$. The electropherogram, obtained on this apparatus, injecting the standard mixture in hydrodynamic mode for $1 \mathrm{sec}$, is shown in Figure 4. Repeatability of migration time is ranging from $0.32 \%$ to $0.52 \%$.

\section{Conclusion}

Proposed method was developed for the simultaneous determination of nine water-soluble vitamins $\left(B_{1}, B_{1 a}, B_{2}, B_{2 a}\right.$, $\mathrm{B}_{3}, \mathrm{~B}_{5}, \mathrm{~B}_{6}, \mathrm{~B}_{9}$, and $\mathrm{B}_{10}$ ) in the multivitamin pharmaceutical formulations by CZE. The best resolution was obtained

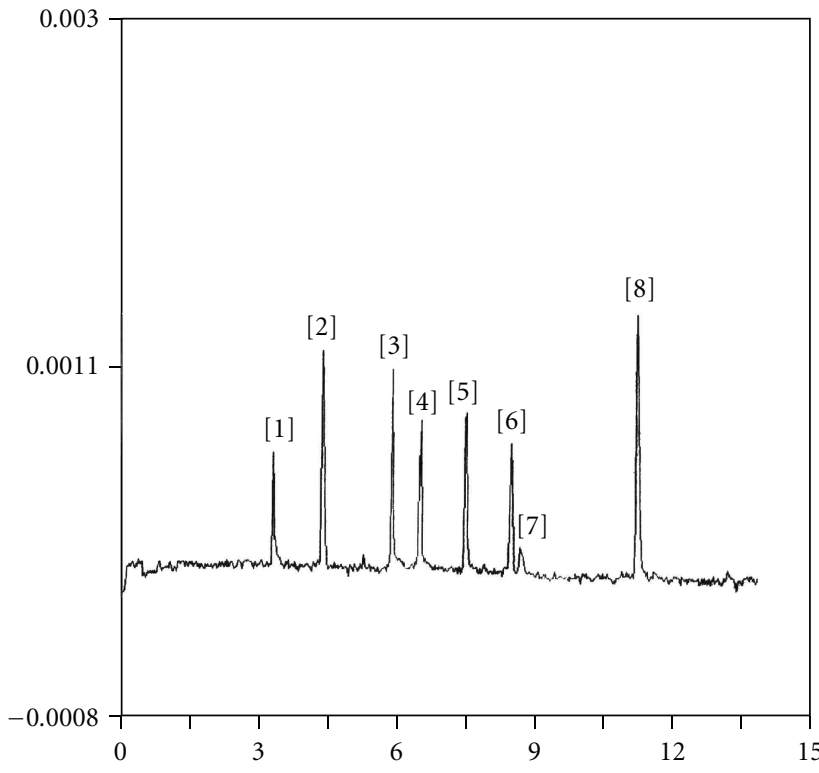

FIGURE 4: Electropherogram of standard mixture. Peak identification: (1) $\mathrm{B}_{1}$, (2) $\mathrm{B}_{3}$, (3) $\mathrm{B}_{2}$, (4) $\mathrm{B}_{6}$, (5) $\mathrm{B}_{1 \mathrm{a}}$, (6) $\mathrm{B}_{10}$, (7) $\mathrm{B}_{5}+\mathrm{B}_{2 \mathrm{a}}$, (8) $\mathrm{B}_{9}$. The vitamin concentrations are the same as in Figure 2. Experimental conditions: borate buffer $20 \mathrm{mM}$; $\mathrm{pH}=9,2 ; V=$ $10 \mathrm{kV} ; i=17 \mu \mathrm{A} ; T=25^{\circ} \mathrm{C}$; hydrodynamic injection $t_{i n j}=1 \mathrm{~s}$; fused silica capillary ID $=50 \mu \mathrm{m} ; L=44 \mathrm{~cm} ; l=36 \mathrm{~cm}$; instrument Spectra Phoresis 1000.

in about 9 min using a simple tetraborate buffer $20 \mathrm{mM}$, $\mathrm{pH}=9.2$ at $25^{\circ} \mathrm{C}$, and constant voltage of $20 \mathrm{kV}$ in uncoated fused silica capillary. The method is suitable for the vitamins B analysis as the validation confirmed: it is precise, accurate, and rugged. The analyses of real samples proved its applicability. Since no expensive reagent and no pretreatment of samples are required in this procedure, it offers a valid alternative for quality control analysis in the pharmaceutical industry.

\section{References}

[1] Z. Chen, B. Chen, and S. Yao, "High-performance liquid chromatography/electrospray ionization-mass spectrometry for simultaneous determination of taurine and 10 water-soluble vitamins in multivitamin tablets," Analytica Chimica Acta, vol. 569, no. 1-2, pp. 169-175, 2006.

[2] S. Vidović, B. Stojanović, J. Veljković, L. Pražić-Arsić, G. Roglić, and D. Manojlović, "Simultaneous determination of some water-soluble vitamins and preservatives in multivitamin syrup by validated stability-indicating high-performance liquid chromatography method," Journal of Chromatography A, vol. 1202, no. 2, pp. 155-162, 2008.

[3] N. Liu, D. Chen, H. Tang, H. Yu, and L. Li, "Simultaneous determination by high performance liquid chromatography of water-soluble vitamins in powdered milk for infants of eight species," Fenxi Ceshi Xuebao, vol. 27, no. 4, pp. 408-411, 2008.

[4] P. F. Chatzimichalakis, V. F. Samanidou, R. Verpoorte, and I. N. Papadoyannis, "Development of a validated HPLC method for the determination of B-complex vitamins in pharmaceuticals and biological fluids after solid phase extraction," Journal of Separation Science, vol. 27, no. 14, pp. 1181-1188, 2004. 
[5] B. Klejdus, J. Petrlová, D. Potěšil et al., "Simultaneous determination of water- and fat-soluble vitamins in pharmaceutical preparations by high-performance liquid chromatography coupled with diode array detection," Analytica Chimica Acta, vol. 520, no. 1-2, pp. 57-67, 2004.

[6] K. Li, "Simultaneous determination of nicotinamide, pyridoxine hydrochloride, thiamine mononitrate and riboflavin in multivitamin with minerals tablets by reversed-phase ionpair high performance liquid chromatography," Biomedical Chromatography, vol. 16, no. 8, pp. 504-507, 2002.

[7] R. Amidžić, J. Brboric, O. Čudina, and S. Vladimirov, "RPHPLC determination of vitamins $B_{1}, B_{3}, B_{6}$, folic acid and $B_{12}$ in multivitamin tablets," Journal of the Serbian Chemical Society, vol. 70, no. 10, pp. 1229-1235, 2005.

[8] W. Chen, J. Ye, and W. Tian, "Determination of thiamine and riboflavin in "Duoweiyansu" tablet by HPLC," Zhongguo Yaoye, vol. 17, no. 5, pp. 18-19, 2008.

[9] S. Buskov, P. Møller, H. Sørensen, J. C. Sørensen, and S. Sørensen, "Determination of vitamins in food based on supercritical fluid extraction prior to micellar electrokinetic capillary chromatographic analyses of individual vitamins," Journal of Chromatography A, vol. 802, no. 1, pp. 233-241, 1998.

[10] M. S. Bellini, G. Manetto, Z. Deyl, F. Tagliaro, and I. Mikš́k, "Capillary electrophoretic separation of vitamins in sodium dodecyl sulfate containing buffers with lower aliphatic alcohols and n-hexane as organic modifiers," Journal of Chromatography B, vol. 741, no. 1, pp. 67-75, 2000.

[11] D. Rajzer, E. Sell, and A. Kraczkowska, "Determination of vitamins of the B group in "Vitaminum B Compositum" by capillary zone electrophoresis," Annales Academiae Medicae Gedanensis, vol. 31, pp. 89-94, 2001.

[12] D. Rajzer, E. Sell, A. Kraczkowska, and K. Sawicz, "Identification and determination of vitamins of the $\mathrm{B}$ group in "extract of Equisetum arvense with vitamins" by capillary zone electrophoresis," Annales Academiae Medicae Gedanensis, vol. 32, pp. 293-300, 2002.

[13] R. Huopalahti and J. Sunell, "Use of capillary zone electrophoresis in the determination of B vitamins in pharmaceutical products," Journal of Chromatography, vol. 636, no. 1, pp. 133$135,1993$.

[14] S. Boonkerd, R. Detaevernier, and Y. Michotte, "Use of capillary electrophoresis for the determination of vitamins of the B group in pharmaceutical preparations," Journal of Chromatography $A$, vol. 670, no. 1-2, pp. 209-214, 1994.

[15] S.-C. Su, S.-S. Chou, D.-F. Hwang, P.-C. Chang, and C.-H. Liu, "Capillary zone electrophoresis and micellar electrokinetic capillary chromatography for determining water-soluble vitamins in commercial capsules and tablets," Journal of Food Science, vol. 66, no. 1, pp. 10-14, 2001.

[16] L. Fotsing, M. Fillet, I. Bechet, P. Hubert, and J. Crommen, "Determination of six water-soluble vitamins in a pharmaceutical formulation by capillary electrophoresis," Journal of Pharmaceutical and Biomedical Analysis, vol. 15, no. 8, pp. 1113-1123, 1997.

[17] A. Niazi, J. Zolgharnein, and S. Afiuni-Zadeh, "Spectrophotometric determination of ternary mixtures of thiamin, riboflavin and pyridoxal in pharmaceutical and human plasma by least-squares support vector machines," Analytical Sciences, vol. 23, no. 11, pp. 1311-1316, 2007.

[18] R. C. Barthus, L. H. Mazo, and R. J. Poppi, "UV spectrophotrometry and chemometrics methods for simultaneous determinations of riboflavin $\left(\mathrm{VB}_{2}\right)$, thiamine $\left(\mathrm{VB}_{1}\right)$, pyridoxine $\left(\mathrm{VB}_{6}\right)$ and nicotinamide (VPP)," Quimica Nova, vol. 30, no. 7, pp. 1638-1643, 2007.
[19] A. Gentili, F. Caretti, G. D’Ascenzo et al., "Simultaneous determination of water-soluble vitamins in selected food matrices by liquid chromatography/electrospray ionization tandem mass spectrometry," Rapid Communications in Mass Spectrometry, vol. 22, no. 13, pp. 2029-2043, 2008.

[20] ICH, Harmonised Tripartite Guideline, IFPMA Ed., Geneva, Switzerland, 1994. 


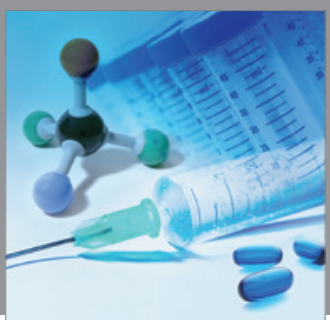

International Journal of

Medicinal Chemistry

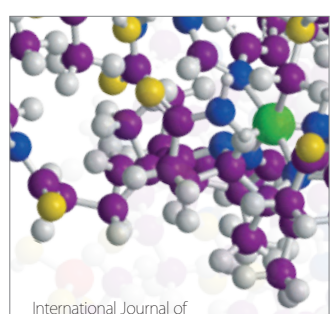

Carbohydrate Chemistry

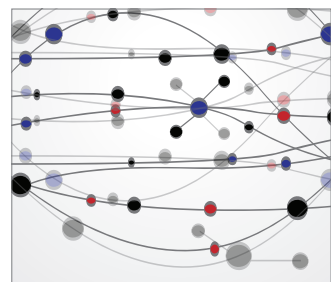

The Scientific World Journal
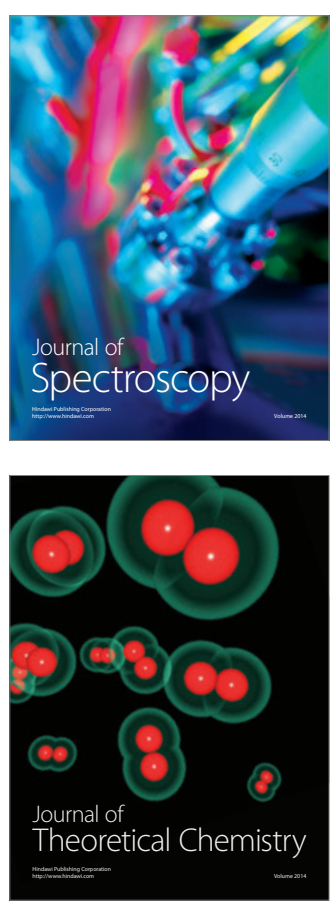
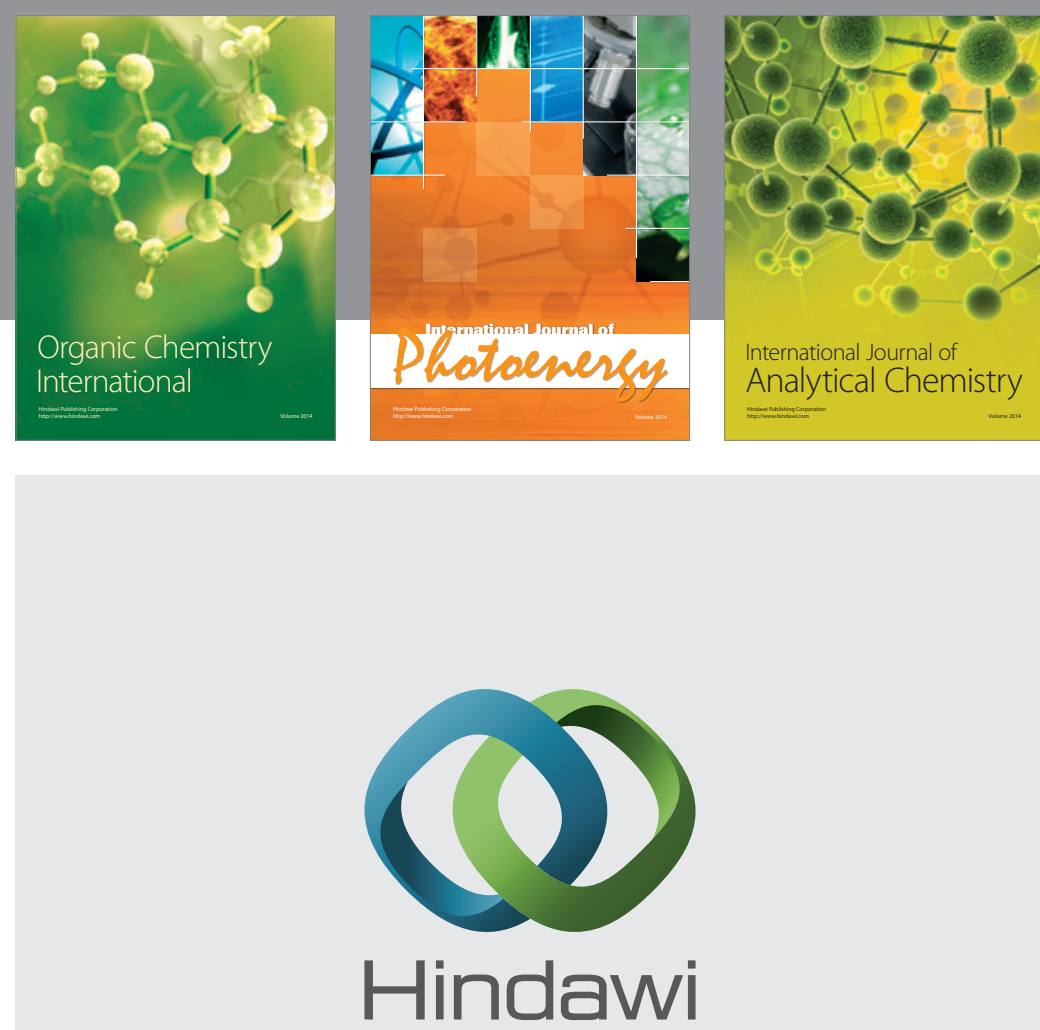

Submit your manuscripts at

http://www.hindawi.com
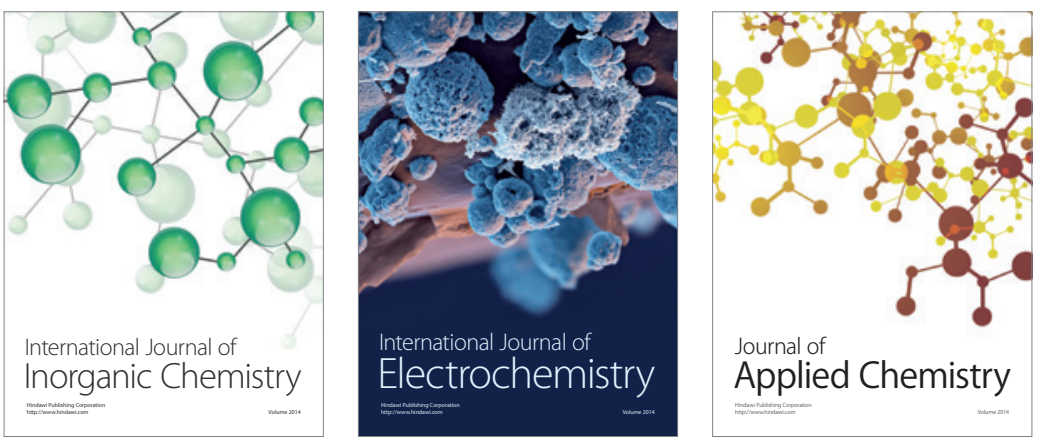

Journal of

Applied Chemistry
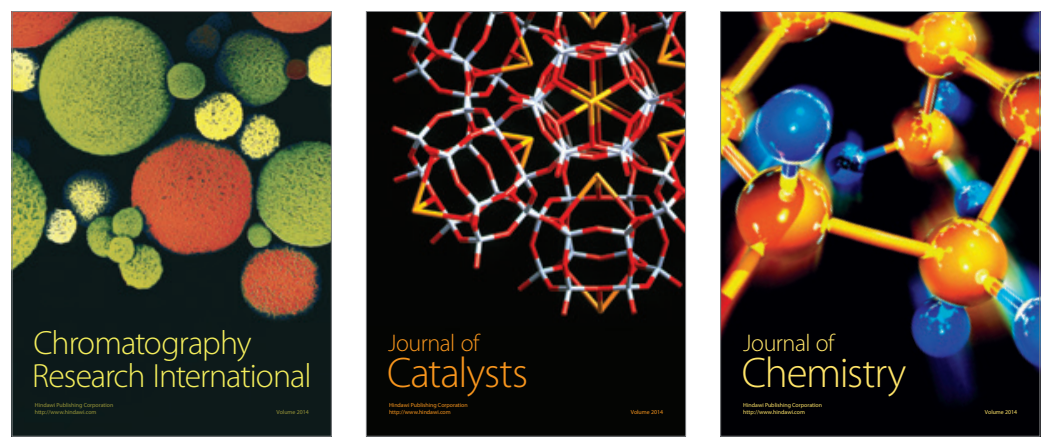
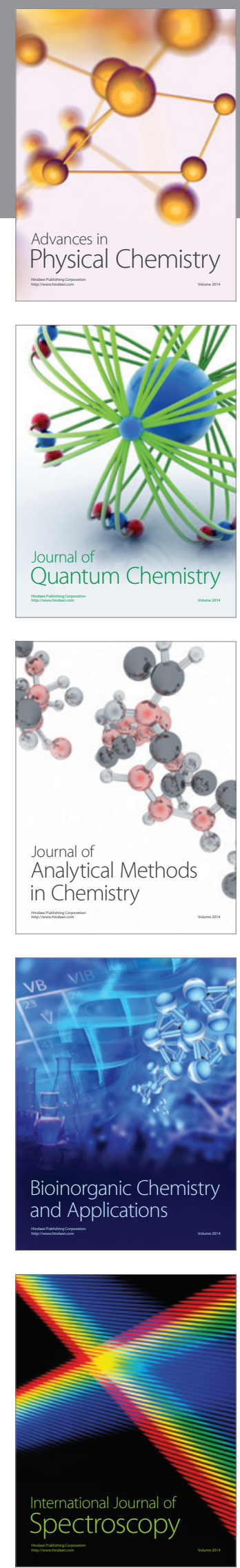